This item was submitted to Loughborough's Research Repository by the author.

Items in Figshare are protected by copyright, with all rights reserved, unless otherwise indicated.

\title{
Entry level RP machines: how well can they cope with geometric complexity?
}

PLEASE CITE THE PUBLISHED VERSION

http://dx.doi.org/10.1108/01445151111117737

PUBLISHER

(C) Emerald

VERSION

AM (Accepted Manuscript)

LICENCE

CC BY-NC-ND 4.0

REPOSITORY RECORD

Pei, Eujin, R.I. Campbell, and D.J. de Beer. 2019. "Entry Level RP Machines: How Well Can They Cope with Geometric Complexity?". figshare. https://hdl.handle.net/2134/9763. 
This item was submitted to Loughborough's Institutional Repository (https://dspace.lboro.ac.uk/) by the author and is made available under the following Creative Commons Licence conditions.

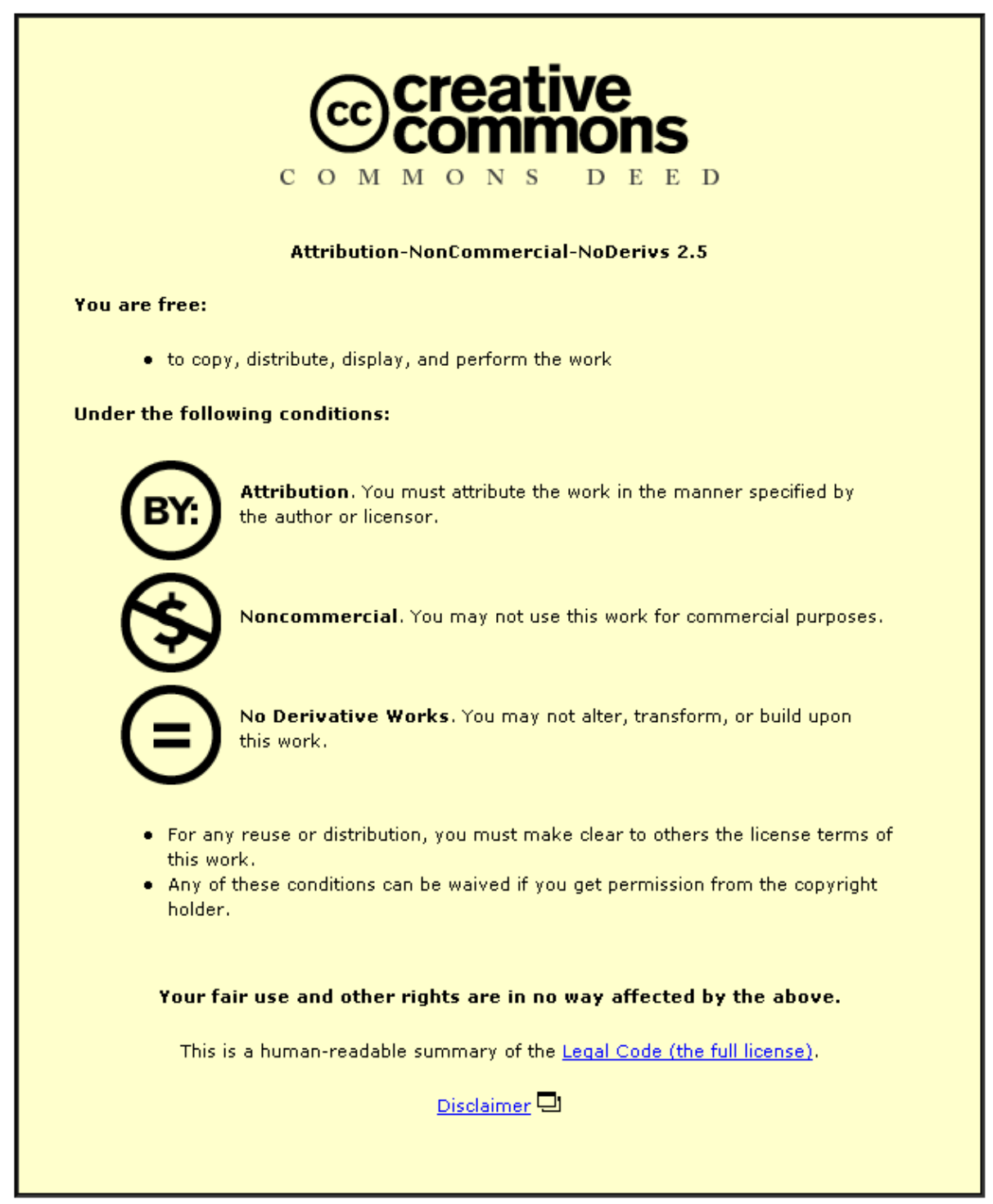

For the full text of this licence, please go to: http://creativecommons.org/licenses/by-nc-nd/2.5/ 


\title{
Entry Level RP Machines: How Well Can They Cope With Geometric Complexity?
}

\section{Pei E, Campbell RI, De Beer DJ}

\author{
Type of Paper: \\ Research Paper
}

\section{Purpose:}

The purpose of this paper was to examine the limitations of entry level RP (ELRP) machines when fabricating objects with high complexity.

\section{Methodology:}

The literature review provides an overview of RP technologies, followed by a discussion on the different levels of complexity in objects. The paper continues with a discussion on the definition of entry level rapid prototyping, followed by a number of experiments to explore the limitations of an entry level RP system when fabricating complex models, and to compare the results obtained with those from a professional RP machine using standardised build parameters and the same ABS material.

\section{Findings:}

Of the five complex models that were produced from the Rapman machine, four of them were affected by warping. The findings also found that support structures were difficult to remove due to the interwoven build pattern. The study also found that the Rapman parts were coarsely built as opposed to the Dimension parts that were less coarse. The Rapman parts were also much lighter due to the hollow internal structure, as compared to the Dimension parts that were virtually solid. From a quantitative viewpoint, parts produced from the Rapman machine showed significantly greater average errors in both absolute and percentage terms.

\section{Practical Implications:}

Users should bear in mind the restrictions of ELRP machines when fabricating complex shapes. The models may be prone to warping and the support structures could be difficult to remove.

\section{Value:}

This article allows developers to understand the restrictions when fabricating complex models on an ELRP machine. The findings will also enable manufacturers to develop better entry level systems.

\section{Keywords:}

Entry Level, Rapid Prototyping, Geometric Complexity 


\section{Introduction}

According to Graham (2000), the use of Rapid Prototyping (RP) has enabled a more efficient process of New Product Development (NPD). RP is the collective name for the set of technologies that include Stereolithography (SLA), Laser Sintering (LS), Fused Deposition Modeling (FDM) and Z-Corporation's Three-Dimensional Printing (3DP); all of which utilise Computer-Aided-Design (CAD) data to build up a physical object. The use of RP is a relatively affordable, effective and fast approach for producing sample parts for products and moulds. These tangible models allow members of a multi-disciplinary team to see, interact with, clarify and evaluate the design (de Beer et al., 2009). Ideas can be vigorously tested since developers are able to fabricate parts to the required resolution. Up until recently, 3DP has been seen as the "entry level" RP process. As reported by Dimitrov et al (2006) and Wohlers (2010), 3DP has been recognised as a "very competitive process in terms of cost and speed", and the number of 3D printing machines sold during 2009 had risen by $18 \%$ over 2008. 3DP systems from Z-Corporporation have a fast fabrication time, a low material cost, the option of colour, and build parts that can be used directly for casting (Azari and Nikzad, 2009). It was also reported that if companies were to invest in RP, the most popular choice (28\%) would be 3DPs (Strategic Direction, 2009).

24-bit full colour prints can also be achieved by many of the 3DP machines from ZCorporation (Dean, 2009). Siemer (2005) noted that the ability to provide highdefinition colour prototypes with labels directly on the model has significantly improved the communication of the design intent among stakeholders in new product development. Despite these improvements in technology, Wohlers (2003) indicated that for RP to better penetrate new markets, systems must become more affordable, easier to use and simpler to maintain. More importantly, the cost of ownership must drop further and quality of materials must improve.

Most RP technologies offer geometric freedom that allows undercuts, overhangs and freeform shapes to be produced (Levy et al., 2003). As low-cost ELRP machines are now gaining in popularity, the aim of this paper is to find out whether complicated objects can be fabricated using these entry level machines. Research is first 
undertaken through a literature review to discuss RP technology, followed by defining levels of complexity that sets the scene for the experiments that were conducted.

\section{Background to Research}

\subsection{Rapid Prototyping}

This section provides a literature review on RP technology, particularly concerning the complexity of 3D objects that can be produced. The use of RP allows components to be fabricated directly from CAD data in the form of a .stl file to handle and transfer data of a part from the CAD system to the RP machine (Kai et al., 1997). RP has redefined the process of NPD by offering geometric freedom that was once impossible with traditional manufacturing or model-making. The use of RP is effective for high-value industries such as automotive, bio-medical and aerospace applications where part complexity is high (Yan et al., 2009). Some common uses of RP in NPD include concept modelling, fit and function testing, tooling trials and customised fabrication of end-use parts (Strategic Direction, 2009). While RP includes a broad spectrum of technologies such as SLA, LS and FDM, this study shall centre on entry level RP machines.

A new trend in RP has emerged recently and can be referred to as entry level RP, which uses machines that are comparatively inexpensive, desktop-sized and usually incorporate an open build chamber. They are gaining popularity among higher education institutions as a learning platform and are used by independent product developers who are unable to afford a full-fledged professional system. In terms of cost, ELRP machines range from US\$520 (RepRap II: Mendel) to US\$2400 (Fab@Home Model 1). At the time of writing, the Fab@Home Model 1 was found to be the most expensive ELRP system, but a second model will soon be released in the market (Fab@Home, 2009). The newer model (Fab@Home Model 2) is expected to cost US\$1300. Entry level systems are usually constructed from selfassembled kits using only basic hobbyist tools and skills, as opposed to commercial machines that are delivered as a fully-assembled system (Marlone and Lipson, 2007). Another key characteristic of entry level systems is the open-source approach where online discussion forums on the internet are available for participants and 
users to share and exchange ideas, provide advice and contribute to the machine control source code. According to Malone and Lipson (2007), such "ubiquitous automated manufacturing opens the door to a new class of independent designers with the ability to directly fabricate functional custom objects". Despite the growing popularity of ELRP systems, very little research has been undertaken to examine the issues or limitations of using them.

For this study, the authors have studied four different ELRP systems to investigate key similarities and differences among them. The four machines were the Bits-fromBytes Rapman 3D (Model 1) <http://www.bitsfrombytes.com>, the Fab@Home Fabber 1 from Massachusetts Institute of Technology (MIT) < http://fabathome.org>, the Replicating Rapid-Prototyper (RepRap II: Mendel) <http://reprap.org> and the Makerbot CupCake CNC <http://www.makerbot.com> (Stevens, 2009). Although the four systems have slightly different performance specifications (Table 1), they possess the same layer-based extrusion technology. In terms of similarity, all four systems are based on a Cartesian $(X, Y, Z)$ 3-axis process and are only capable of producing low-resolution objects. In addition, all of them embrace an open-source approach where information about the hardware and software is available on the internet. This allows developers and the community to be able to openly discuss issues.

\begin{tabular}{|l|l|l|l|l|}
\hline System & $\begin{array}{l}\text { Rapman 3D } \\
\text { (Model 1) }\end{array}$ & $\begin{array}{l}\text { Fab@Home } \\
\text { (Model 1) }\end{array}$ & $\begin{array}{l}\text { RepRap II: } \\
\text { Mendel }\end{array}$ & $\begin{array}{l}\text { Makerbot } \\
\text { CupCake CNC }\end{array}$ \\
\hline Cost & US\$1495 & US\$2400 & US\$520 & US\$750 \\
\hline Build Process & $\begin{array}{l}\text { FFF (Fused } \\
\text { Filament } \\
\text { Fabrication) / } \\
\text { Thermoplastic } \\
\text { extrusion }\end{array}$ & $\begin{array}{l}\text { Syringe-based } \\
\text { extrusion }\end{array}$ & $\begin{array}{l}\text { FFF (Fused } \\
\text { Filament } \\
\text { Fabrication) / } \\
\text { Thermoplastic } \\
\text { extrusion }\end{array}$ & $\begin{array}{l}\text { FFF (Fused } \\
\text { Filament } \\
\text { Fabrication) / } \\
\text { Thermoplastic } \\
\text { extrusion }\end{array}$ \\
\hline Positioning & $\begin{array}{l}\text { Cartesian } \\
(\mathrm{X}, \mathrm{Y}, \mathrm{Z}) \\
\text { 3-axis system }\end{array}$ & $\begin{array}{l}\text { Cartesian } \\
(\mathrm{X}, \mathrm{Y}, \mathrm{Z}) \\
\text { 3-axis system }\end{array}$ & $\begin{array}{l}\text { Cartesian } \\
\text { (X, Y, Z) } \\
\text { 3-axis system }\end{array}$ & $\begin{array}{l}\text { Cartesian } \\
\text { (X, Y, Z) } \\
\text { 3-axis system }\end{array}$ \\
\hline
\end{tabular}




\begin{tabular}{|c|c|c|c|c|}
\hline Input Type & SD Card & $\begin{array}{l}\text { USB } \\
\text { Connection }\end{array}$ & $\begin{array}{l}\text { USB } \\
\text { Connection }\end{array}$ & $\begin{array}{l}\text { SD Card } \\
\text { and USB } \\
\text { Connection }\end{array}$ \\
\hline $\begin{array}{l}\text { Maximum print } \\
\text { dimensions }\end{array}$ & $\begin{array}{l}275 \mathrm{~mm} x \\
205 \mathrm{~mm} x \\
210 \mathrm{~mm}\end{array}$ & $\begin{array}{l}203 \mathrm{~mm} x \\
203 \mathrm{~mm} x \\
102 \mathrm{~mm}\end{array}$ & $\begin{array}{l}200 \mathrm{~mm} x \\
200 \mathrm{~mm} x \\
140 \mathrm{~mm}\end{array}$ & $\begin{array}{l}100 \mathrm{~mm} x \\
100 \mathrm{~mm} x \\
130 \mathrm{~mm}\end{array}$ \\
\hline Print resolution & $0.1 \mathrm{~mm}$ & $0.1 \mathrm{~mm}$ & $0.1 \mathrm{~mm}$ & $0.08 \mathrm{~mm}$ \\
\hline $\begin{array}{l}\text { Printing } \\
\text { Speeds }\end{array}$ & $\begin{array}{l}17.0 \mathrm{~mm}^{3} \\
\text { per second }\end{array}$ & $\begin{array}{l}\text { Depending on } \\
\text { fluidity of } \\
\text { material }\end{array}$ & $\begin{array}{l}15.0 \mathrm{~cm}^{3} \text { per } \\
\text { hour }\end{array}$ & $\begin{array}{l}X / Y \text { feed rate } \\
5000 \mathrm{~mm} \text { per } \\
\text { minute } \\
Z \text { feed rate } 200 \\
\text { mm per minute }\end{array}$ \\
\hline Materials & $\begin{array}{l}\text { ABS, HDPE, } \\
\text { LDPE, PP, } \\
\text { UPVC (in } 3 \mathrm{~mm} \\
\text { filament) }\end{array}$ & $\begin{array}{l}\text { Any kind of } \\
\text { liquid or paste } \\
\text { that can be } \\
\text { dispensed } \\
\text { from a syringe }\end{array}$ & $\begin{array}{l}\text { ABS, PLA, } \\
\text { HDPE, etc (in } \\
3 m m \text { filament) }\end{array}$ & $\begin{array}{l}\text { ABS, PLA, } \\
\text { HDPE, CAPA } \\
\text { (PCL) (in } 3 \mathrm{~mm} \\
\text { filament) }\end{array}$ \\
\hline
\end{tabular}

Table 1: Technical Specifications for the four systems

In terms of differences, the Fab@Home Fabber 1 uses a syringe to extrude material, whereas the other three systems employ thermoplastic extrusion from a filament. There are also variations in terms of input, print dimensions, print resolution and printing speeds. Another significant difference is the cost, where the Fabber 1 is the most expensive and the RepRap II: Mendel is the most affordable. The Rapman 3D Model 1 (Figure 1) was used for this study to examine the limitations of ELRP machines due to its availability and accessibility to the authors. Although the Rapman was used as an example of an ELRP machine, it must be clarified that the results from this study do not aim to generalise the capabilities or limitations of other entry level RP systems in the market. 


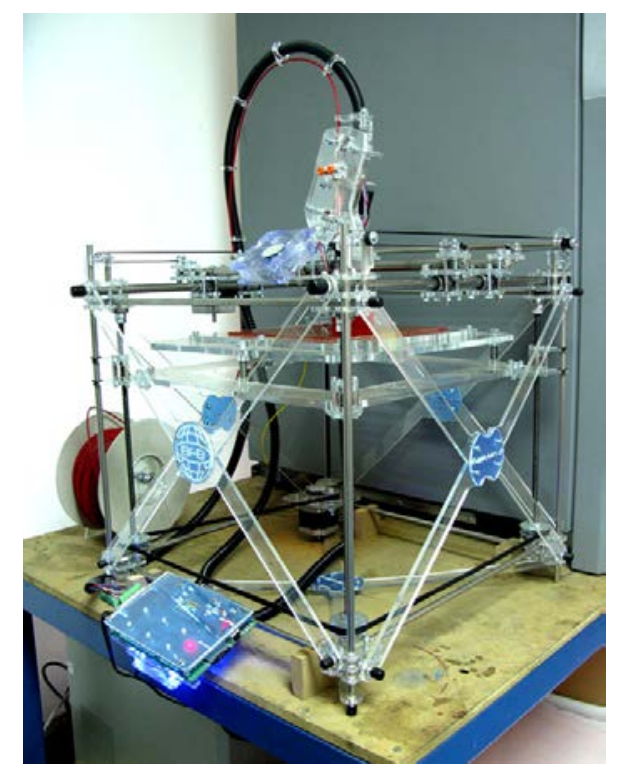

Figure 1: The Rapman 3D System

\subsection{Rapman 3D}

Recognising that most RP systems are an expensive investment, the Rapman machine was developed to allow Computer Aided Manufacturing (CAM) to be made available to schools and tertiary institutions (Rapman, 2009). According to Breslin (2010), the use of affordable RP systems such as the Rapman is now finding a place in education as an important tool in design and technology teaching, where it gives students a sense of feel, fit and sense. The physical manifestation and scale help students understand what the product is going to do and how to redevelop it. The Rapman is also cost-effective it only uses material actually required to build the model, which results in very little waste (Merlin John Online, 2009). Assembling the machine from a kit allows pupils to learn basic engineering principles and the openbox concept lets users see and understand the production process clearly. The process of using the Rapman begins from the 3D CAD model which is saved in the form of an .stl and converted into a set of G-code instructions, which contain the build information for the Rapman. The extruder head is heated to a pre-determined temperature and begins to extrude molten plastic layer by layer to eventually build up a solid model. A variety of materials in filament form can be used, including Acrylonitrile Butadiene Styrene (ABS), Polyvinyl Chloride (PVC), Polyethylene (PE), Polypropylene (PP), Polystyrene (PS), Polycarbonate (PC) and bio-degradable Polylactic Acid (PLA). The build parameters such as temperature, extrusion flow and 
speed of the nozzle are configured in the G-code and can be adjusted from the machine console (Rapman, 2009). Having discussed aspects of RP and the Rapman system, the next section aims to clarify the various levels of complexity present in objects.

\subsection{Levels of Complexity}

For this research, complexity refers to the quality or state of an object in terms of its intricacy and connections (Sukumar et al., 2008). There are several ways of defining the complexity of a model. Among the earliest classification was by Forrest (1974) who proposed 'geometric complexity' in terms of lines, planes, curves, surfaces, etc.; 'combinatorial complexity' that concerned the number of components, edges, faces, etc.; and 'dimensional complexity' in terms of 2D or 3D objects. While RodríguezToro et al. (2002) proposed that complexity could be identified by the level of geometry, topology and assembly, Rossignac (2005) further suggested that complexity can be obtained through computational methods and categorised according to 'algebraic complexity', 'topological complexity', 'morphological complexity', 'combinatorial complexity' or 'representational complexity'.

Some researchers have proposed the use of algorithms to evaluate the complexity of an object (Gero and Kazakov, 2004; lyer et al., 2006; Jayanti et al., 2006; and Wang 2008). Valentan et al. (2008) also proposed four approaches by means of simple equations to define the complexity of a 3D CAD model. For their study, they used six different forms including a prism, rib, plug, housing, holder and wheels. In the first method, they proposed that a rough evaluation of the shape complexity, not considering the size or volume, could be made by determining the number of triangles (or facets) within the .stl data through a CAD program (Valentan et al. 2006).

The second method was to calculate the ratio between the volume and the surface which could also be calculated from the CAD software. Thirdly, shape complexity could be found by calculating the ratio of the block volume to the parts volume. Finally, they proposed that complexity could be obtained by calculating the ratio of the volume to the number of facets. While the first method was the simplest 
approach, this was a subjective estimate being dependent on the export resolution of the CAD file. The second and third methods are similar and do not present accurate results. The more accurate method was the fourth approach which used the ratio of the volume to the number of facets (ibid).

While researchers have suggested that the complexity of an object could be defined from a computational or statistical perspective, Heaps and Handel (1999) argued that the complexity could be based more simply through perception about its connectedness, depth, orientation and structure. More recently, Sreenivas et al. (2008) undertook a series of trials that examined the perceptual complexity of objects concerning its geometry. They found that complexity was directly related to the variation of the curvature whereby sharper and unexpected curves contributed to increased complexity. Secondly, the number of parts was significantly and directly proportional to the complexity of an object. Thirdly, objects and surfaces with lesser or no symmetry were defined as being most complex. Lastly, the number of protrusions, holes and intricate details also increased the complexity. For this research, the complexity of objects is defined using a perceptual approach in terms of intricacy and connections (ibid). Simple objects would possess planar surfaces with minimal variation in curvature and having multiple axes of symmetry. In contrast, complex objects would consist of intricate details with a number of holes and with little symmetry and variations on the surface.

\section{Experimental Work}

\subsection{Objectives of the Experiments}

The objectives of the experiments were to explore the limitations of an entry level RP system when fabricating complex models, and to compare the results obtained with those from a professional RP machine. The method was to use the Rapman as an example of an entry level machine and the Dimension SST from Stratasys as an example of a professional RP machine. Both machines work on an extruded filament basis but there is an order of magnitude difference in their costs. In terms of experimental limitations, only one build was conducted for each model and therefore the study does not really address the aspect of process variability. In order to provide a greater level of consistency in the experiments, the ELRP machine was used with 
identical settings in terms of extrusion flow $(20.7 \mathrm{~mm} / \mathrm{s})$, nozzle heat $\left(245^{\circ} \mathrm{C}\right)$ and nozzle head speed $(64.0 \mathrm{~mm} / \mathrm{s})$ with the same type of extrusion material (Acrylonitrile butadiene styrene) and bed surface (perspex bed) throughout the trials. In addition, all of the experiments took place in the same well-ventilated indoor space at room temperature. The models on the Dimension machine were all built at the same time, in the controlled environment of a sealed build chamber.

Having defined complexity by means of a perceptual approach, five 3D CAD models were modelled using the Inventor CAD software from AutoDesk. They comprised a spiral-pillared arch, a spinal vertebra bone, a simple gear system, a bag buckle and a pair of pliers. The key features of the five models are summarised in Table 2. From the five CAD models, the next step was to fabricate them on the Rapman system and record any issues that were observed.

\begin{tabular}{|c|c|c|c|c|c|}
\hline Name & $\begin{array}{c}\text { Spiral-pillared } \\
\text { arch }\end{array}$ & Spine bone & Gear system & Bag buckle & Pliers \\
\hline \multicolumn{6}{|l|}{ Image } \\
\hline $\begin{array}{l}\text { Complexity } \\
\text { Feature }\end{array}$ & $\begin{array}{l}\text { Variation of } \\
\text { curvature, four } \\
\text { connected } \\
\text { pillars }\end{array}$ & $\begin{array}{l}\text { Variation of } \\
\text { curvature, } \\
\text { intricate } \\
\text { details }\end{array}$ & $\begin{array}{l}\text { number of } \\
\text { protrusions }\end{array}$ & $\begin{array}{l}\text { Deeply } \\
\text { recessed } \\
\text { undercut }\end{array}$ & $\begin{array}{l}\text { Presence of } \\
\text { protrusions } \\
\text { and holes }\end{array}$ \\
\hline $\begin{array}{l}\text { Objective } \\
\text { of Test }\end{array}$ & $\begin{array}{l}\text { To investigate } \\
\text { if the four } \\
\text { pillars could } \\
\text { be connected } \\
\text { without } \\
\text { support } \\
\text { structures }\end{array}$ & $\begin{array}{l}\text { To investigate } \\
\text { if detailed } \\
\text { surfaces can } \\
\text { be fabricated } \\
\text { with the use of } \\
\text { support } \\
\text { structures }\end{array}$ & $\begin{array}{l}\text { To investigate } \\
\text { if parts can be } \\
\text { fabricated with } \\
\text { sufficient } \\
\text { accuracy to } \\
\text { allow meshing }\end{array}$ & $\begin{array}{l}\text { To investigate } \\
\text { if support } \\
\text { structures } \\
\text { could be } \\
\text { removed from } \\
\text { the recesses }\end{array}$ & $\begin{array}{l}\text { To investigate } \\
\text { if fabricated } \\
\text { parts can be } \\
\text { assembled }\end{array}$ \\
\hline
\end{tabular}

Table 2: 3D CAD models and description of their complex features 


\subsection{Fabrication of CAD Models with the Rapman Machine}

As an initial trial run prior to fabricating the five models, a simple rectangular solid with a chamfered edge and hollow area was produced on the Rapman ELRP machine (Figure 2).

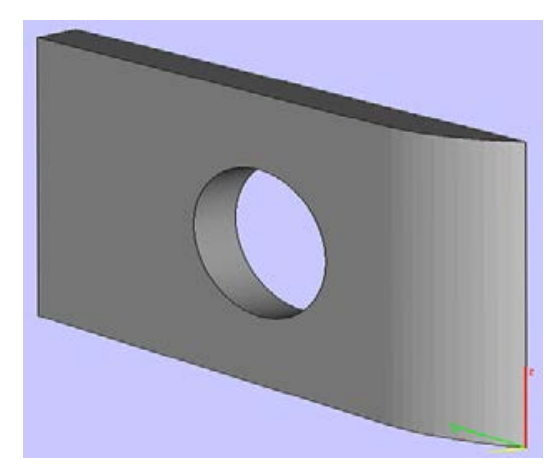

Figure 2: Rectangular solid

During fabrication, it was found that the extruded polymer (ABS) did not sufficiently adhere to the bed surface. A series of improvisations were made, including the use of solvent, double-sided adhesive tape and roughening the surface with sandpaper, all of which increased the bonding. With further tests, it was found that raising the raft base temperature from $200^{\circ} \mathrm{C}$ to $245^{\circ} \mathrm{C}$ also improved the build quality (Figure 3). Having successfully completed the first print, the five complex models were produced.

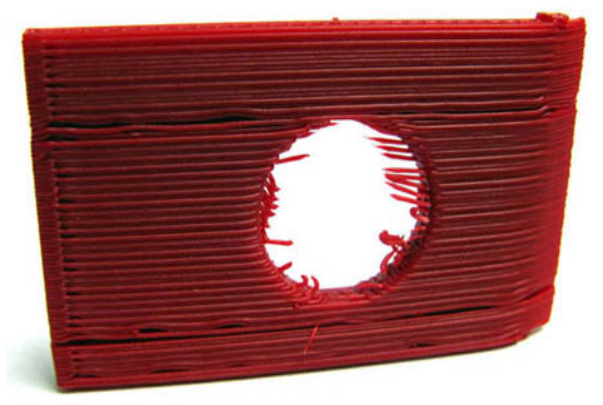

Figure 3: Completed model

\subsubsection{Spiral-pillared Arch}

The complexity of the spiral-pillared arch is shown in the multiple variations of curvature and having four pillars joined in the middle. The objective was to 
investigate whether the spiral profiles and four pillars could be built and connected without the need for support structures. As this was the first complex model to be fabricated, a single arch was first attempted. During fabrication, due to the tall profile and small raft base area, the model became unstable. The solution was to increase the adhesion of the base surface by adding additional adhesive tape. The results were satisfactory, following which a second thinner model was built. When the results were once again satisfactory, the final model was fabricated without any problems except for some slight warping that was observed at the raft layer (Figure 4). This experiment showed that multiple spiral profiles and separated areas in proximity could be joined without the need for support structures.

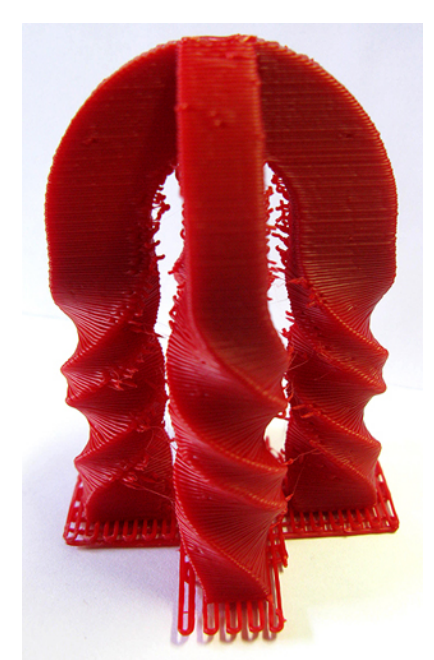

Figure 4: Final model of Spiral-pillared Arch

\subsubsection{Spinal Vertebra Bone}

The complexity of the vertebra lay in having multiple variations of curvature with very intricate surface details. It was observed that the bone geometry was overhanging in most areas and hence the need for support structures arose. The objective of the experiment was to ascertain if complicated surfaces could be fabricated with the use of support structures. Some warping on the raft layer was observed as shown in Figure 5. Despite the warping, the experiment showed that detailed surfaces with overhanging parts could be fabricated with the addition of support structures. 


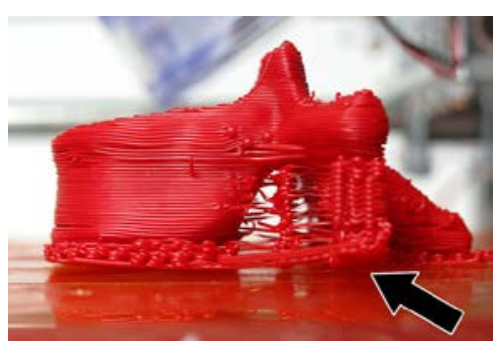

Figure 5: Warping on raft layer

\subsubsection{Gear System}

The gear system model contained a high level of rotational symmetry with little variation in surface curvature that would initially classify it as a simple object. However, the complexity lay in the large number of protrusions and holes. The objective was to investigate whether the components could be fabricated with a degree of accuracy that would allow the gears to mesh. Due to the large surface area of the base, a large amount of warping occurred as shown in Figure 6. The bow warp along the length of the face was a result of shrinkage from the rapid and uneven cooling of the plastic. Several methods including accelerating and reducing the rate of extrusion flow; and increasing and decreasing the temperature of the nozzle proved to be ineffective in reducing this effect. Despite the severe warping, the parts were assembled together with no major issues.

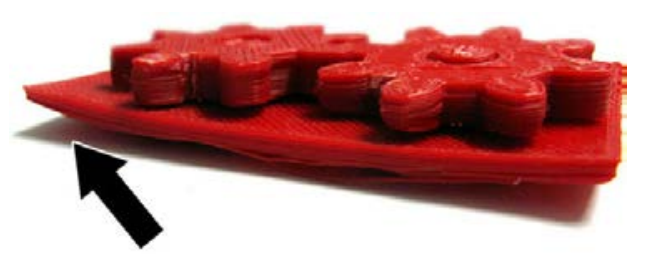

Figure 6: Warping on the base of gear system

\subsubsection{Bag Buckle}

The bag buckle contains deep and recessed undercuts that required a need for tightly-woven support structures. The objective was to investigate if these internal structures could be easily removed and whether the two parts could fit securely together. Due to the relatively small surface area, no warping was observed and the only issue was the removal of the support material. It was resolved by carefully using a penknife to carve out the internal support material. The two buckle components fitted together reasonably well ((Figure 12). 


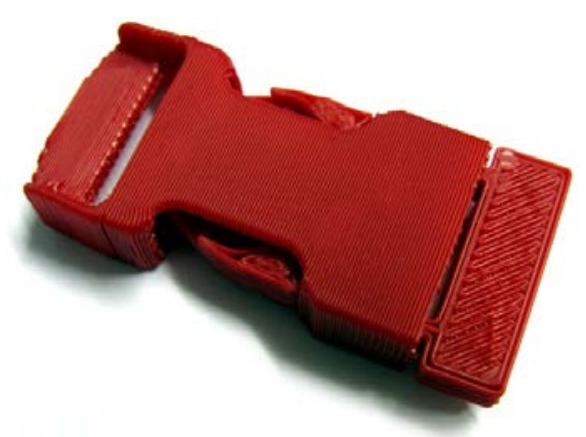

Figure 12: Fitting of bag buckle components

\subsubsection{A Pair of Pliers}

The pliers were the last parts to be built on the Rapman machine. The parts contained several protrusions and holes which categorised it as a complex model. The objective was to investigate whether the pieces could be assembled as a functional prototype. Due to the lengthwise dimension, some bow warping was observed on the arms. Despite the minor warping, the components were put together and there were no issues with the assembly (Figure 13).

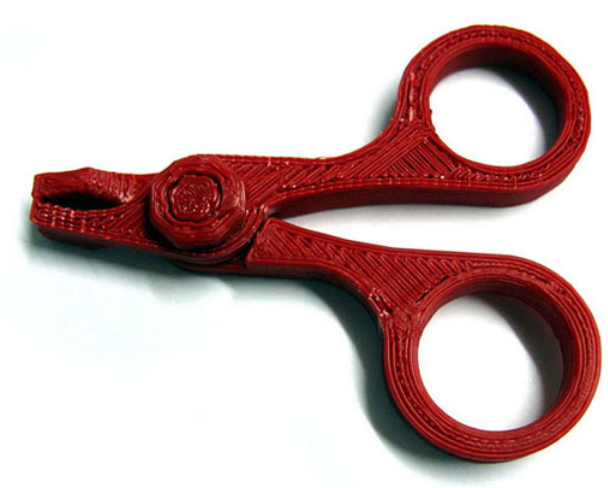

Figure 13: Assembled pliers

\subsection{Comparison with Models built on the Dimension Machine}

The same .stl files as used previously were processed to create a single build platform on a Dimension SST machine using standardised build parameters for the Stratasys supplied ABS material (Figure 14). One unexpected issue that occurred was the failure of the bag buckle parts to build correctly. This was traced to the .stl file which did not represent a single solid object but rather a series of unconnected surfaces. This had not proved a problem for the Rapman processing software, which had been able to generate usable G-code instructions. The build platform was 
immersed in an agitated caustic solution for several hours to remove all of the soluble supports that had been automatically built with the part models. A second issue observed was a degree of warping on the gear system base part (Figure 15). This was not nearly as extensive as with the Rapman machine but served to demonstrate that even with a heated build envelope, fabrication of large flat areas of thermoplastic material can cause problems.

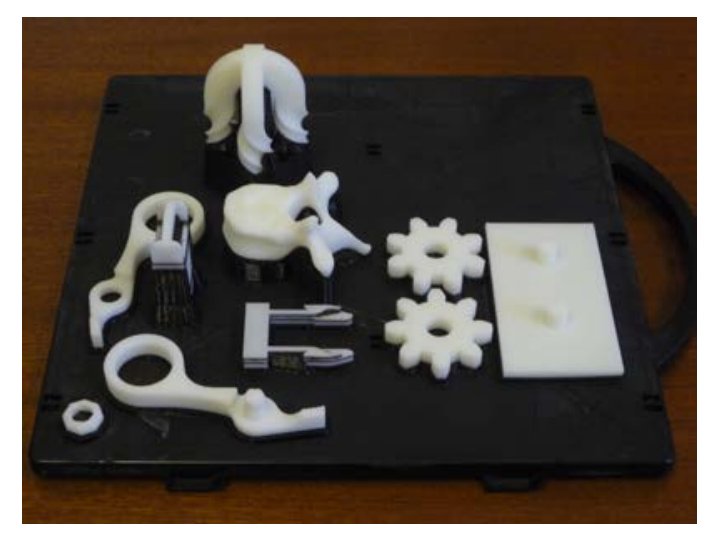

Figure 14: Dimension parts on Single Build Platform

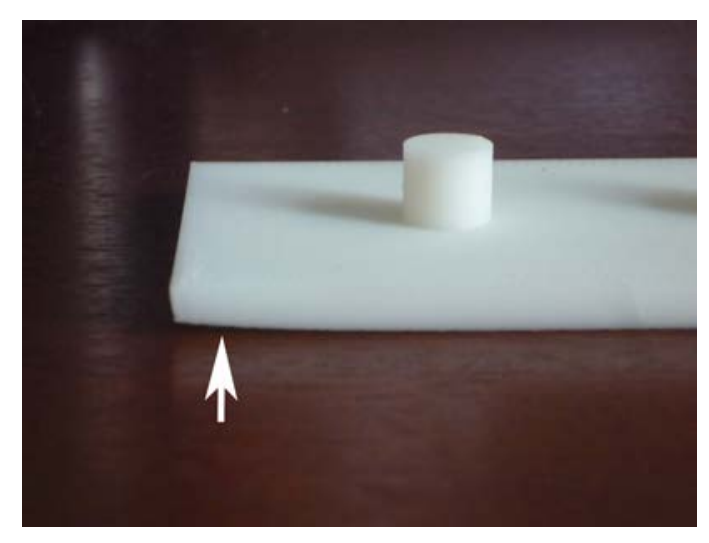

Figure 15: Warping on Gear System Base Part

The sets of parts obtained from the Rapman machine and the Dimension machine were subjected to both qualitative and quantitative comparative analyses. From a qualitative viewpoint, the obvious differences between the parts were threefold. Firstly, the Rapman parts had numerous "strings" of material coming off their surfaces (see Figure 4) whereas the Dimension parts were very "clean". Secondly, 
the surface roughness of the Rapman parts was noticeably worse, mainly due to the thicker layers used $(0.4 \mathrm{~mm}$ compared to $0.25 \mathrm{~mm})$. Thirdly, the Rapman parts were much lighter because they had been built with a hollow internal structure to reduce build time, whereas the Dimension parts were virtually solid.

For the quantitative comparative analysis, three key dimensions were identified on each part and measured to two decimal places using a set of digital Vernier callipers. The dimensions were typically those from major features of the parts that would determine their functionality. The total number of dimensions measured for each set of parts was thirty. The difference between each measured dimension and the "exact" CAD model dimension was calculated (always expressed as a positive value) and then converted to a percentage error. Table 3 shows the average values of both absolute and percentage errors for the Rapman and Dimension parts. The Rapman machine demonstrates significantly greater average errors in both absolute and percentage terms. An interesting phenomenon that was revealed by this analysis was that the Dimension machine would more often build oversize dimensions (20 out of 30) whereas the Rapman would more often build undersize dimensions (23 out of 30).

\begin{tabular}{|l|l|l|}
\hline Machine & Average Absolute Error & Average Percentage Error \\
\hline Rapman & $0.54 \mathrm{~mm}$ & $1.90 \%$ \\
\hline Dimension & $0.19 \mathrm{~mm}$ & $0.94 \%$ \\
\hline
\end{tabular}

Table 3: Comparative Error Results for Rapman and Dimension machines.

\section{Discussion}

Two major issues were encountered with the Rapman parts - warping and the difficult removal of internal support material. Warping occurred between the bed and the raft surface, as well as between the raft surface and the actual component. From the experiments, four out of five of the objects, with the exception of the bag buckle, 
experienced warping. To reduce the incidence of surface warp in ELRP systems, developers are proposing the use of Polylactic acid (PLA) material (Makerbot 2010) or the installation of a heated chamber or bed (Keegan, 2010; Bits from Bytes, 2010). Despite these suggestions, the heating accessories are not yet commercially available.

The difficult removal of internal support material was another issue that was encountered during this study. When fabricating the spine bone, the support material was produced on the external surface and they could be easily removed. However, the bag buckle contained a deep cavity that made the removal of support material very difficult. The support material was carved out with a scalpel, and it was a lengthy process. Removing support material is still a manual process and standard solution has yet been offered by vendors. However, developers are now beginning to offer the option of a second nozzle that could be incorporated into the Rapman machine. Therefore, a suggestion would be to use the supplementary nozzle to eject a support material that could be soluble.

The relatively low quality of the models produced by the RapMan machine in comparison to the Dimension machine means that they would be inherently unsuitable for professional design or engineering practice. They are more suited to educational and home hobbyist usage.

\section{Conclusion}

As entry level RP systems gain popularity in the industry, the next generation of machines will continue to provide low ownership costs with an acceptable degree of quality. This paper has provided an overview of RP technology, centring on ELRP systems. This was followed by defining objects according to their level of complexity, leading to experiments with five models with complex features that showed variations in curvature, inter-connected parts, intricate details, protrusions, holes and deeply recessed undercuts. These parts were built both on a Rapman machine and a Dimension SST machine. While the Rapman machine was found to be capable of producing low-resolution objects, two major issues existed. They include the problem of warping and the need to manually remove support structures. Other issues were 
poorer dimensional accuracy and surface roughness. The results of this study through the use of the Rapman system should not be generalised as the capabilities of a low entry RP machine. Further research could investigate the use of different materials to examine the impact on warping. Future work on a wider scale could also examine how other parameters such as the temperature of the material and the build pattern could affect the build quality of parts produced from an entry level RP machine.

\section{References}

Azari A. and Nikzad S. (2009) "The evolution of rapid prototyping in dentistry: A Review", Rapid Prototyping Journal Vol. 15 No. 3 pp. 216-225

Bits from Bytes (2010) "Heated Bed" http://www.bitsfrombytes.com/ora/user/ index.php?topic=398.0 (Accessed 1 March 2010)

Breslin, S. (2010) "Vision: Looking at the Future of Learning" FutureLab publication January-June, Futurelab, Bristol pp. 4-6

de Beer, D. J., Campbell, R. I., Truscott, M., Barnard, L. J. and Booysen G. J. (2009) "Client-centred design evolution via functional Prototyping" International Journal of Product Development Vol. 8 No. 1 pp. 22-41

Dean, A. (2009) "Z Corporation ZPrinter 650" <http://develop3d.com/reviews/zcorporation-zprinter-650> (Accessed 1 March 2010)

Dimitrov, D., Schreve K. and de Beer, N. (2006) "Advances in three dimensional printing - state of the art and future perspectives" Rapid Prototyping Journal Vol. 12 No. 3 pp. $136-147$

Fab@Home (2009) "Fab@Home: Overview" <http://fabathome.org/wiki/index.php? title=Fab\%40Home:Overview> (Accessed 1 March 2010)

Forrest, A. R. (1974) "Computational Geometry - Achievements and Problems" In Shikhare, D., 2001, Complexity of Geometric Models. National Centre for Software Technology: Mumbai.

Gero, J. S. and Kazakov, V. (2004) "On measuring the visual complexity of 3D objects" Journal of Design Sciences and Technology Vol. 12 No. 1 pp. 35-44.

Graham, S. (2000) "Rapid Prototyping: A Key to Fast Tracking Design to Manufacture" Assembly Automation, Vol. 20 No. 4 pp. 291-294

Heaps, C. and Handel, C. H. (1999) "Similarity and Features of Natural Textures" Journal of Experimental Psychology: Human Perception and Performance No. 25 pp. 299-320. 
lyer N. and Jayanti, S. (2006) "An Engineering Shape Benchmark for 3D models", $<$ https://engineering.purdue.edu/.../DevelopingAnEngineeringShapeBenchmarkForC adModels> (Accessed 1 March 2010)

Jayanti, S., Kalyanaraman, Y., Iyer, N. and Ramani, K. (2006) "Developing an Engineering Shape Benchmark for CAD Models" Computer-Aided Design No. 38 pp. 939-953

Kai, C. C., Gan G., Jacob, K. and Mei, T. (1997) "Interface Between CAD and Rapid Prototyping Systems. Part 2: LMI - An Improved Interface" The International Journal of Advanced Manufacturing Technology No. 13 pp. 571-576

Kegan, J. (2010) "Just another Reprap" <http://www.keegan.org/reprapblog/> (Accessed 1 March 2010)

Levy, G. N., Schindel, R. and Kruth, J. P. (2003) "Rapid Manufacturing and Rapid Tooling with Layer Manufacturing (LM) Technologies, State of the Art and Future Perspectives", CIRP Annals - Manufacturing Technology, Vol. 52, No. 2 pp. 589-609

Malone E. and Lipson H. (2007) "Fab@Home: The personal desktop fabricator kit" Rapid Prototyping Journal Vol. 13 No. 3 pp. 245-255

Merlin John Online (2009) "Rise of the machines - the RapMan cometh" $<$ http://www.agent4change.net/innovation/innovation/246-rise-of-the-machines-therapman-cometh.html> (Accessed 1 September 2010)

Rapman USA (2009) "Rapman FAQs", <http://www.rapmanusa.com/rapmanFAQ.html> (Accessed 1 March 2010)

Rodriguez-Toro, C. A., Tate, S. J., Jared, G. E. M., and Swift, K. G. (2002) "IMECE2002-39413 Shaping the Complexity of a Design." ASME; Design Engineering Division, New Orleans, L. pp. 641-650

Rossignac, J. (2005) "Shape complexity" The Visual Computer Vol. 21 No. 12 pp. 985-996.

Siemer, M. (2005) "Mydea Technologies commissions first three-dimensional color rapid prototyping technology" Assembly Automation Vol. 25 No. 4 (Company News)

Stevens, M. (2009) "Will Lower 3D Printer Prices Aid Growth?" $<$ http://www.rapidtoday.com/a1-technologies.html> (Accessed 1 March 2010)

Strategic Direction (2009) "The Maturing of Rapid Prototyping: Market for Additive Fabrication Passes \$1billion", Strategic Direction Vol. 25 No. 8 pp. 38-40

Sukumar, S., Page, D., Koschan, A. and Abidi, M. (2008) "Towards Understanding What Makes 3D Objects Appear Simple or Complex," in Proc. IEEE Conference on Computer Vision and Pattern Recognition CVPR 2008, Sixth IEEE Workshop on Perceptual Organization in Computer Vision (POCV), Anchorage, Alaska, June, 2008. 
Valentan, B., Brajlih, T., Drstvensek, I. and Balic, J. (2008) Basic Solutions on Shape Complexity Evaluation of STL Data" Journal of Achievements in Materials and Manufacturing Engineering Vol. 26 No. 1 pp. 73-80

Valentan, B., Brajlih, T., Drstvensek, I. and Balic, J. (2006) "Evaluation of Shape Complexity Based on STL Data", Journal of Achievements in Materials and Manufacturing Engineering Vol. 17 No. 1-2 pp. 293-296

Wang, D. (2008) "3D Shape Complexity Using View Similarity" Diploma Thesis in Computer Science, University of Saarland Max-Planck-Institut für Informatik, Computer Graphics Group

Wohlers, T. (2010), "Wohlers Report 2010: State of the Industry Report Annual Worldwide Progress Report", Wohlers Associates, Inc., Fort Collins.

Wohlers, T. (2003), "Wohlers Report 2003: State of the Industry Report Annual Worldwide Progress Report", Wohlers Associates, Inc., Fort Collins.

Yan, Y., Li, S., Zhang, R., Lin, F., Wu, R., Lu, Q., Xiong, Z. and Wang, X. (2009) "Rapid Prototyping and Manufacturing Technology: Principle, Representative Technics, Applications, and Development Trends", Tsinghua Science \& Technology Vol. 14 No. 1pp. 1-12 